\title{
Determination of the roll-off value in the air- gapped inductor of a DC-DC boost converter circuit with FEA parametric simulations
}

\author{
P. ARIKAN, S. BALCI and F. BATTAL
}

\begin{abstract}
The electromagnetic behavior of the inductors used as passive circuit elements directly affects the electrical and mechanical performance of the power electronics circuits. In general, when using inductor core structures with/without airgap length in the classical design process, the dynamic effects of the inductance value are not considered in the design stage. However, the inductance value may change during the operation of the circuit due to electrical and magnetic parameters of the inductor, and this change is called roll-off value of the inductance. In this study, the roll-off value has been determined graphically and numerically based on mechanical parameters (such as air-gap length) and electrical parameters (such as winding turns and DC current amplitude) for an air-gapped ferrite $E$ core designed with finite element analysis (FEA) software. Thus, not only the inductance value has been calculated in the design stage but also the roll-off value during the operation of the circuit has been reported with the parametric simulation studies.
\end{abstract}

Index Terms-FEA parametric simulations, gapped-core, inductor parameters, roll-off value.

\section{INTRODUCTION}

$\mathrm{N}$ OWADAYS, advanced power electronics application area is growing with the tendency to use renewable energy sources and they are frequently used in daily life with current applications such as electric vehicles [1]. In this context, with the advances in semiconductor technology, both power electronics circuit topologies are developing, and

PINAR ARIKAN, is with Department of Engineering Sciences, Karamanoğlu Mehmetbey University, Karaman, Turkey, (e-mail: pnryrlky@gmail.com ).

iD https://orcid.org/0000-0002-7974-9289

SELAMI BALCI, is with Department of Electrical and Electronics Engineering, Karamanoğlu Mehmetbey University, Karaman, Turkey, (email: sbalci@kmu.edu.tr).

(iD https://orcid.org/0000-0002-3922-4824

FUNDA BATTAL, is with Department of Electronics and Automation Nevşehir HacıBektaş Veli Univesity, Nevsehir, Turkey, (e-mail: fundacodur@gmail.com ).

(iD) https://orcid.org/0000-0002-7233-2843

Manuscript received December 23, 2019; accepted Mar 3, 2020.

DOI: $\underline{10.17694 / \text { bajece. } 664044}$ innovations are provided in magnetic circuit elements in these topologies [2]. The design concept of the magnetic circuit elements has been revised in order to provide smaller size and less power losses [3] with the development of the soft magnetic materials. Especially in the modern design approach, the most suitable design can be reached shortly before the prototype production with the development of software that enables electromagnetic modeling by finite element method, and the revolution in solver performance in computer hardware.

The inductors used in DC-DC power converter circuits are known as DC inductors and are exposed to the high frequency ripple on the DC current. The flux density in the inductor core appears to be triangular ripple wave depending on the peak value of the current, and the inductance value is dynamically similar to this ripple wave [4-6]. In the design of the airgapped inductor, the analysis of bad effects such as the fringing flux effects during the determination of the air-gap length can be expressed mathematically in classical design approach. However, for the effects of the air-gap parts on the dynamic inductance and roll-off values of the inductor, electromagnetic modeling facilitates the design process [7].

The software used for electromagnetic modeling with finite element analysis (FEA) is often used to determine the electromagnetic, thermal and cooling performance of the inductor before prototype production. In context, Dang et al. [8] present the electromagnetic modeling, FEA simulation and design stage of a high-power inductor for battery charge system in order to reduce the core volume for electric vehicle. For the thermal coupled FEA, Du et al. [9] present in order to determine an inductor on both its electromagnetic and thermal behavior. Munguia et al. [10] explain how designers can take advantage of the useful features of electromagnetic FEA software to quickly model nonlinear behavior inductors and determine their performance. In addition, software developed in recent years, such as Ansys-Electronics, enables the analysis of both electromagnetic components and power electronics circuits together for the inductor design in power electronics circuits.

In this study, roll-off value of the ferrite core inductor has been determined with the parametric FEA software based on mechanical and electrical parameters for air-gapped E core designed for a DC-DC boost converter circuit. The graphs of the incremental inductance changes based on parametric DC current have been obtained with Ansys-Electronics Desktop 
2019R3, and roll-off values of the designed inductor have been determined. In addition, flux distributions in the inductor core have been visualized and saturation effect has been examined. Thus, not only the inductance value calculated during the design phase, but also the dynamic inductance value during the operation of the circuit has been reported with the simulation studies.

\section{THEORETICAL ANALYSIS OF THE INDUCTANCE VALUE IN INDUCTORS WITH AIR-GAPPED CORE}

In order to obtain the desired inductance value in air gap inductor design, Eq.(1) can be written according to the initial permeability value for effective permeability $\left(\mu_{\text {eff }}\right)$ [11-12].

$$
\mu_{e f f}=f\left(\mu_{i}, H_{c}, B_{s a t}\right)
$$

The magnetic field intensity $\left(H_{c}\right)$ and saturation flux density $\left(B_{\text {sat }}\right)$ values and initial permeability $(\mu \mathrm{i})$ values of the core material are very important, and this information can be reached from the core material datasheet. The basic parameters and the magnetic equivalent circuit for a given airgapped core are given in Fig. 1. Here, the magnetomotor force NI as flux and the reluctances in the path of flux are core and air gap resistance elements as $\Re_{\mathrm{c}}$ and $\mathfrak{R}_{\mathrm{g}}$, respectively [13].

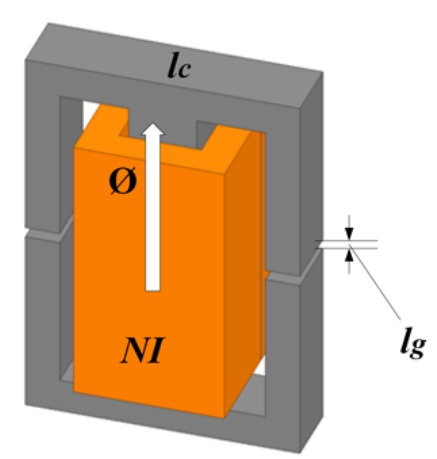

(a)

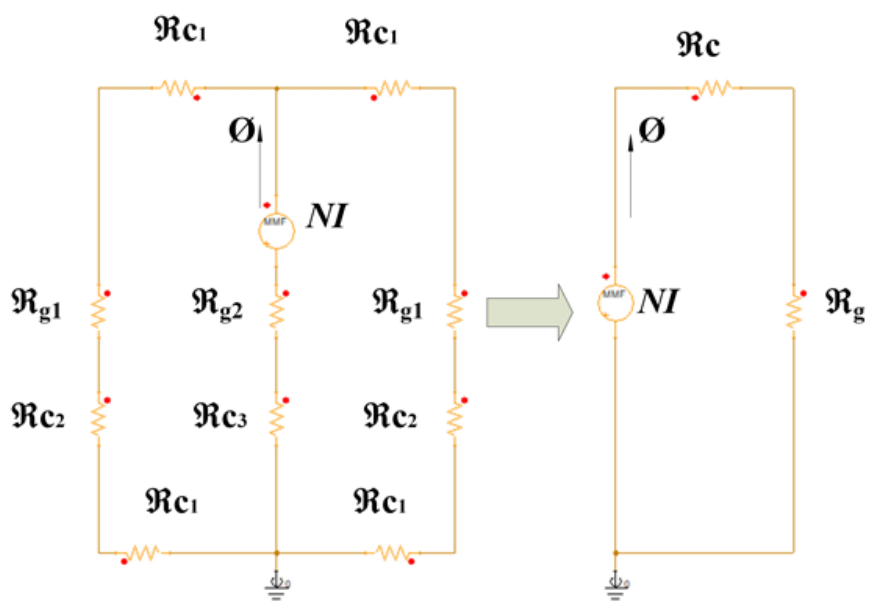

(b)

Fig.1. For the air gapped inductor, (a) basic magnetic parameters and (b) equivalent magnetic circuit [14]
As the ferrite $\mathrm{N} 87$ ferrite core material [15] can be seen in the B-H curve given in Fig. 2, the saturation is delayed by the air gaps in the core in large current $\left(\mathrm{NI}_{\text {sat2 }}\right)$ inductor designs to provide a soft saturation flux characteristic. However, although saturation can be delayed by air gaps, sharp saturation occurs only after a certain current value in materials such as ferrite, amorphous, nanocrystalline and $\mathrm{Si}-\mathrm{Fe}$. In powder materials such as Kool M $\mu$, MPP and XFlux, there is no need to determine the air gap length in the core structures and a soft saturation occurs with the distributed air gap feature [16-17].

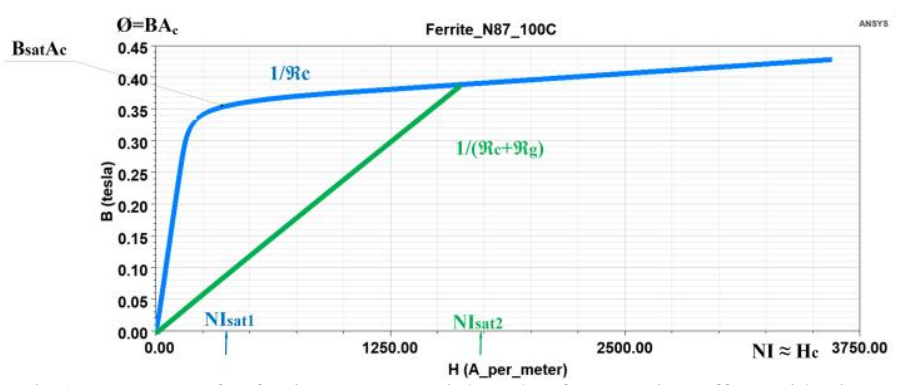

Fig.2. B-H curve for ferrite core material, and soft saturation effect with airgapped core structure $[11,15]$

According to Ampere's law, the relationship between air gap effect and closed-circuit magnetic field can be expressed in Eq.(2) [11].

$$
\oint_{\text {closed }- \text { path }} H \cdot d l=F_{c}+F_{g}
$$

The magnetomotor force can be modeled as an electrical circuit with the Amper-Winding (NI) value of the inductor and the reluctance values in the air-gapped inductor core (Fig. 1). Thus, Eq.(3) can be written for the flux (Ф) circulating in the core [11].

$$
N \cdot I=\Phi\left(\mathfrak{R}_{c}+\mathfrak{R}_{g}\right)
$$

In order to calculate the core and air gap reluctance values, in Eqs. (4-5), since the permeability of the air is $\mu_{0}=4 \pi 10^{-7}$ $\mathrm{H} / \mathrm{m}$, very high reluctance occurs in the air gap parts of the inductor core. Since the core permeability $\mu_{\mathrm{c}}$ is very large compared to the gap, the reluctance of the core remains at very small values [16-17].

$$
\begin{gathered}
\mathfrak{R}_{c}=\frac{l_{c}}{\mu_{c} A_{c}} \\
\mathfrak{R}_{g}=\frac{l_{g}}{\mu_{0} A_{g}}
\end{gathered}
$$

The inductors are energy storage magnetic circuit elements and the stored energy (W) can be expressed as in Eq. (6) [18]. 


$$
W=\frac{1}{2} L I^{2}=\frac{1}{2} \oint_{v} \vec{H} \cdot \vec{B} d v
$$

where: $\mathrm{v}$ - is the volume of the inductor core.

The magnetic field strength is equal to the energy calculated by the closed-loop inductance and the square of the current as $\mathrm{H}$ and flux density B. The Faraday equation given in Eq.(7) can be written to determine the flux value in the core [11].

$V(t)=-n \frac{d \Phi}{d t}=-L \frac{d i}{d t}$

From this, Eq.(8) can be written proportional to the square of the number of turns for the induced voltage due to the equivalent reluctance [11].

$V(t)=\frac{N^{2}}{\mathfrak{R}_{c}+\mathfrak{R}_{g}} \cdot \frac{d i}{d t}$

Thus, for the inductance value and saturation flux value in air-gapped inductor design, Eq.(9) and Eq.(10) can be given [19].

$$
\begin{gathered}
L=\frac{N^{2}}{\mathfrak{R}_{c}+\mathfrak{R}_{g}} \\
\Phi_{\text {sat }}=B_{\text {sat }} \cdot A_{c}
\end{gathered}
$$

In this situation, the current value which can cause saturation of the air-gapped inductor core can be determined by Eq. (11) [11].

$$
I_{s a t}=\frac{B_{s a t} \cdot A_{c}}{N}\left(\Re_{c}+\mathfrak{R}_{g}\right)
$$

Thus, the effective permeability value of the core structures designed with the air gap can be determined by the mean length of the core, the permeability of the inductor core and the air gap length as given by Eq.(12) [7, 20].

$$
\mu_{e f f}=\frac{l_{c}}{\frac{l_{c}}{\mu_{c}}+l_{g}}
$$

Furthermore, the required air gap length Eq.(13) may be calculated in the inductor designed with air gap for a given core cross sectional area $\left(\mathrm{A}_{\mathrm{c}}\right)$ and the desired inductance value (L) [7].

$$
l_{g}=\left(\frac{0.4 \pi N^{2} A_{c}\left(10^{-8}\right)}{L}\right)-\left(\frac{l_{c}}{\mu_{c}}\right),[\mathrm{cm}]
$$

However, depending on the air gap length, there are deviations in the inductance value due to the fringing flux effect. It is therefore more convenient to use multiple air openings and distributed air-gap parts instead of leaving one large air-gap part in the core. The core window height $(G)$ or winding length has a great effect on the fringe flux. Accordingly, the fringing flux factor $(\mathrm{F})$ can be calculated by Eq.(14) [20].

$$
F=\left(1+\frac{l_{g}}{\sqrt{A_{c}}} \ln \frac{2 G}{l_{g}}\right)
$$

Since the fringing flux effect reduces the equivalent reluctance value in air-gapped core structures, an inductance value is higher than the inductance value calculated in Eq.8. Therefore, the inductance value in the proportion to the fringing flux factor increases as shown in Eq. (15) [7, 20].

$L=F\left(\frac{0.4 \pi N^{2} A_{c}}{l_{g}+\frac{l_{c}}{\mu_{c}}} \cdot 10^{-8}\right)$

\section{INDUCTOR DESIGN PARAMETERS WITH THE AIR-GAPPED FERRITE CORE}

The variables that should be considered in the design process as electrical and mechanical variables in air gap inductors for power electronics circuits are given in Table 1. In order to determine the dynamic inductance value according to this table, a number of specific parameters such as DC-DC boost converter switching frequency and inductor current ripple, which are designed for a certain power value, were utilized.

TABLE I

Technical specifications for DC-DC boost converter inductor [2]

\begin{tabular}{|l|l|}
\hline Power Density & $5 \mathrm{~kW}$ \\
\hline Input Voltage $\left(\mathrm{V}_{\mathrm{i}}\right)$ & $200 \mathrm{~V}$ \\
\hline Output Voltage $\left(\mathrm{V}_{\mathrm{o}}\right)$ & $400 \mathrm{~V}$ \\
\hline Load Current $\left(\mathrm{I}_{0}\right)$ & $12.5 \mathrm{~A}$ \\
\hline Inductance $(\mathrm{L})$ & $1 \mathrm{mH}$ \\
\hline Inductor current $\left(\mathrm{I}_{\mathrm{L}}\right)$ & $25 \mathrm{~A} / 22.5 \mathrm{~A}-27,5 \mathrm{~A}$ \\
\hline Ripple Magnitude $\left(\Delta \mathrm{I}_{\mathrm{L}}\right)$ & $5 \mathrm{~A}$ \\
\hline Switching Frequency $\left(\mathrm{f}_{\mathrm{s}}\right)$ & $20 \mathrm{kHz}$ \\
\hline Duty Ratio $(\mathrm{D})$ & 0.5 \\
\hline Core Material & Ferrit 3C90 \\
\hline Core Structure & E1006028 \\
\hline
\end{tabular}

In order to maintain the continuous conduction mode (CCM) [21-22] in DC-DC boost converter circuits, the critical inductance value of inductors should not fall below the critical value in the equation given by Eq.(16) [23].

$$
L_{c}=L=\frac{D(1-D) R_{L}}{2 f_{s}}
$$


where: $\mathrm{D}$ - is defined as the switching duty ratio;

$\mathrm{RL}$ - is load resistance value;

$\left(f_{\mathrm{s}}\right)$ - is the switching frequency.

For this purpose, before the inductor prototype, parametric DC current test can be performed to determine the inductance stability. Thus, the inductance stability or roll-off values can be obtained. Although the roll-off values for core materials are specific in the manufacturer's datasheets, inductance stability has nonlinear behavior and the inductance stability may vary from classical mathematical methods to the operation of the circuit. If the inductance value starts to collapse well below the desired current value in the design stage, the electrical and mechanical parameters must be changed. For example, increasing the air gap length and changing the number of turns. However, such revisions are both costly and unnecessarily prolong the design process. In such cases, 3D electromagnetic modeling enables the inductor to be modeled in a virtual environment close to real conditions.

The theoretical flux distribution of the DC-DC boost converter inductor for the dynamic inductance in the core can be defined by the dynamic minor loop B-H curve as shown in Fig. 3.

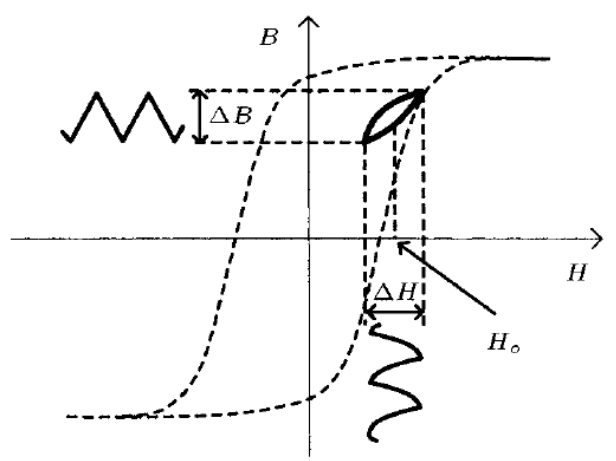

Fig.3. Dynamic minor loop of the inductor flux density [11, 23-24]

In this curve, for the flux density ripple ( $\Delta \mathrm{B})$, Eq.(17) can be explained under ripple superimposed DC excitation. The DC current $\left(\mathrm{I}_{0}\right)$ and the number of turns $(\mathrm{N})$ multiplied by the average magnetic circuit length $\left(l_{c}\right)$ and Eq.(18), the magnetic field strength fluctuation $(\Delta \mathrm{H})$ was obtained [24-25].

$$
\begin{aligned}
& \Delta B=\frac{1}{N A_{c}} \int_{0}^{D T_{s}} v_{L} d t \\
& \Delta H=\frac{N I_{o}}{l_{c}}
\end{aligned}
$$

Where $\mathrm{D}$ is the duty ratio of the power electronics circuit, and $\mathrm{T}_{\mathrm{s}}$ is the switching signal period. Thus the $\mathrm{DT}_{\mathrm{s}}$ is the conduction period of the power switches.

\section{PARAMETRIC SIMULATION STUDIES WITH FEA SOFTWARE}

The parametric simulation studies have been performed with linear steps using FEA software according to electrical $\left(\mathrm{N}\right.$ and $\left.\mathrm{I}_{\mathrm{dc}}\right)$ and mechanical variables $\left(l_{\mathrm{g}}\right)$ given in Table 2. Thus, the dynamic inductance value of an inductor designed with E1006028 core can be easily determined. In addition, in order to ensure inductance stability, the air gap length can be optimized mechanically in order to prevent saturation at a certain number of turns and DC current value.

TABLE II

Electrical and mechanical parameters of air gap

\begin{tabular}{|c|c|c|}
\hline Parameters & Range & Linear Step \\
\hline$l_{\mathrm{g}}$ & $0-3 \mathrm{~mm}$ & $0.50 \mathrm{~mm}$ \\
\hline $\mathrm{N}$ & $50-80 \mathrm{turns}$ & 5 turns \\
\hline $\mathrm{I}_{\mathrm{dc}}$ & $0-40 \mathrm{~A}$ & $2 \mathrm{~A}$ \\
\hline
\end{tabular}

According to these values, parametric simulation studies were carried out with Ansys-Electronics Desktop 2019.R3 software in Maxwell 3D section. For this purpose, E1006028 core material was modeled in three dimensions according to datasheet content [15] and B-H values of ferrite core material were defined in the software library.

A three-dimensional graph based on the parametric DC current increase and winding number values over a given air gap length provides useful information for the designers to determine the inductance value (Fig. 4). According to this graph, DC current value winding number and saturation effect can be seen clearly. The green zones in the graph can be defined as acceptable roll-off values $(60 \%)$ for the desired inductance value. Thus, the parametric inductance values have been determined with the 3D electromagnetic modeling and more realistic conditions [26].
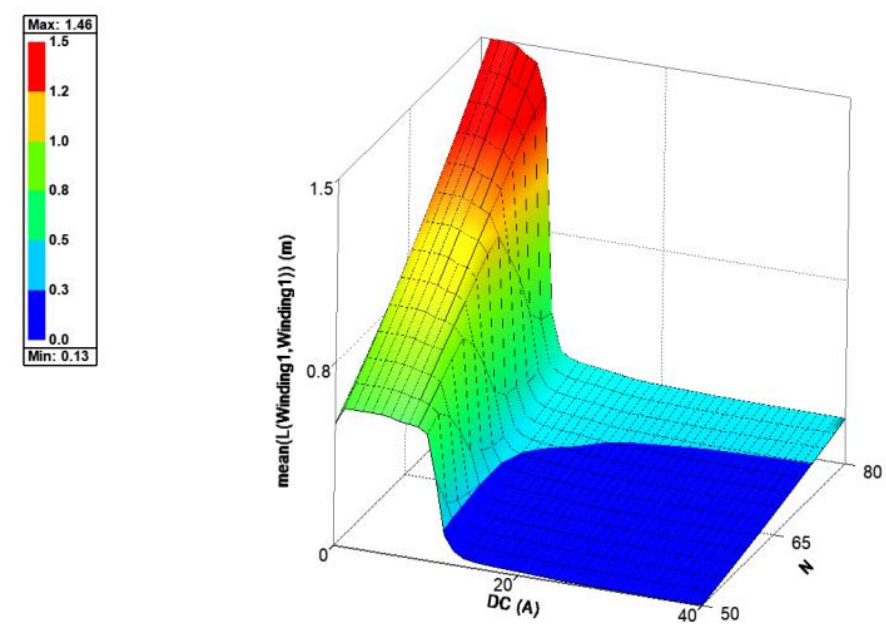

Fig.4. Parametric 3D inductance change graph of designed ferrite core with air gap for maximum $1.5 \mathrm{mH}$

The flux linkage graph, which is defined as winding flux in inductors, shows the electromagnetic behavior of the airgap designed core. According to this graph given in Fig. 5, the green areas for acceptable roll-off values were determined as $0.01-0.015 \mathrm{Weber} / \mathrm{m}^{2}$. This condition, when visualized as the useful flux circulating in the core, does not cause any saturation for ferrite core material with about 0.2 Tesla. For 
ferrite core material, the saturation flux value is given as 0.36 $\mathrm{T}$ in the datasheet [15], and the $0.2 \mathrm{~T}$ flux value for the $20 \mathrm{kHz}$ switching frequency is very useful.
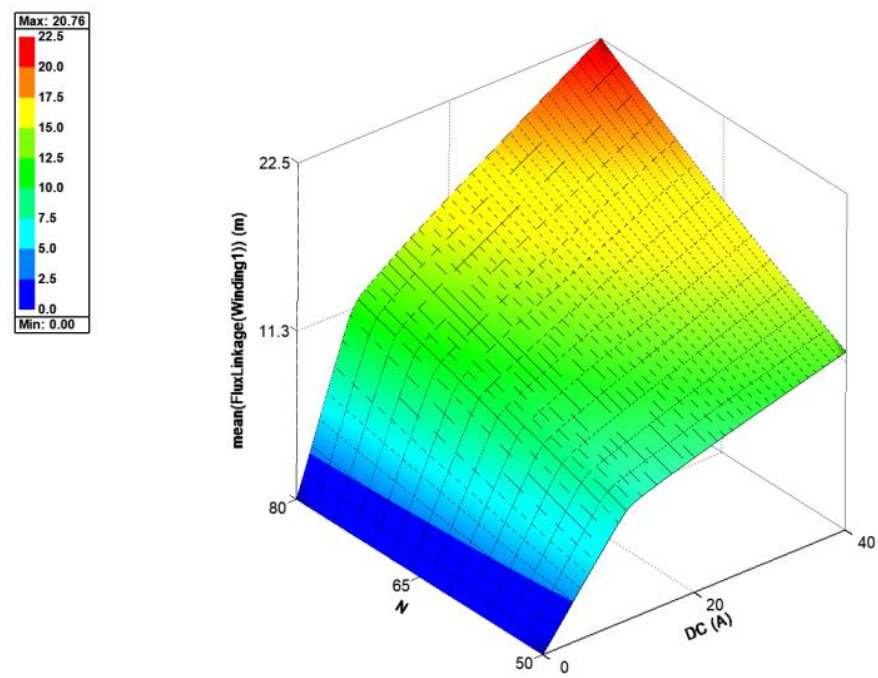

Fig.5. Parametric 3D flux linkage graph of ferrite core designed with the air gap for maximum $22.5 \mathrm{mWeber} / \mathrm{m}^{2}$

When the air gap length is changed, the number of turns of the inductor windings is also changed to achieve the desired inductance value. For example, in the case of $1.5 \mathrm{~mm}$ air-gap in $l_{\mathrm{g} 2}$, the number of turns is 57 turns, whereas in the case of $1_{\mathrm{g} 1}=3 \mathrm{~mm}$ air-gap, 72 turns are sufficient according to the simulation studies. These values are obtained in parametric 3D graphics. Thus, as can be seen in the roll-off graphs given in Figure 6, the dynamic inductance values have been determined according to the air gap lengths $\lg 1$ and $1_{\mathrm{g} 2}$. After $10 \mathrm{~A}$ with dc current increase, roll-off in $1_{\mathrm{g} 2}=1.5 \mathrm{~mm}$ air gap core decreases to $40 \%$ and inductance value decreases too much. However, in the case of $l_{\mathrm{g} 1}=3 \mathrm{~mm}$ air gap, the roll-off has been determined as $60 \%$ and the inductance value is stable even after a current of 10 A DC, thus providing a soft saturation effect.

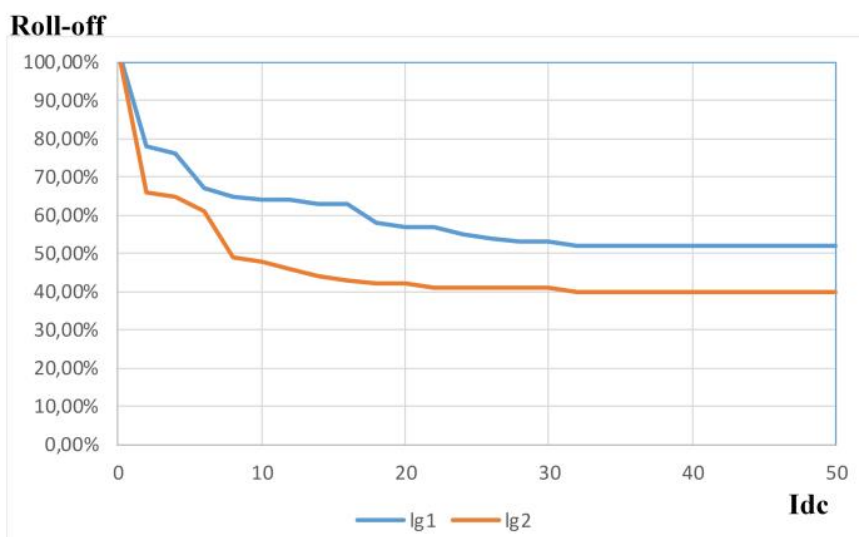

Fig.6. Roll-off values due to DC current increase for ferrite core designed with different air gap length

\section{Power EleCtronics Circuit Performance Analysis WITH FEA CO-SIMULATION}

The link in the simulation circuit Ansys-Twin Builder software given in Fig. 7 is defined with Maxwell 3D software, for the power electronics circuit performance test of the inductor electromagnetic modeling and inductance stability and roll-off values are determined in dynamic behavior. Thus, both the realistic behavior of the designed inductor and the performance of the power electronics circuit can be determined.

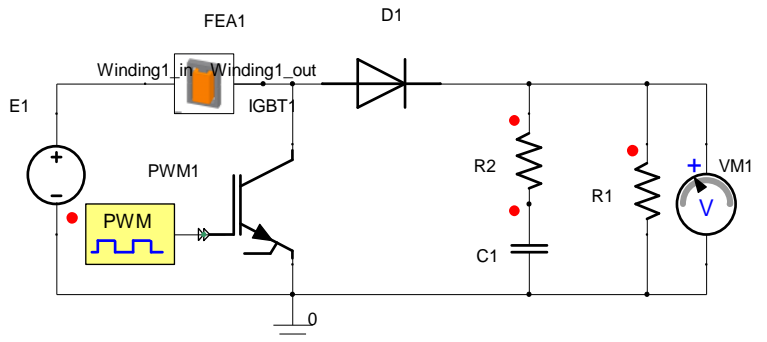

Fig.7. The co-simulation circuits of DC-DC Boost Converter with airgapped inductor

The inductor current graph obtained according to the cosimulation results is shown in Fig. 8 with the ripple value given in Table 1. Thus, the performance of the designed inductor is revealed, and a continuous transmission mode can be provided.

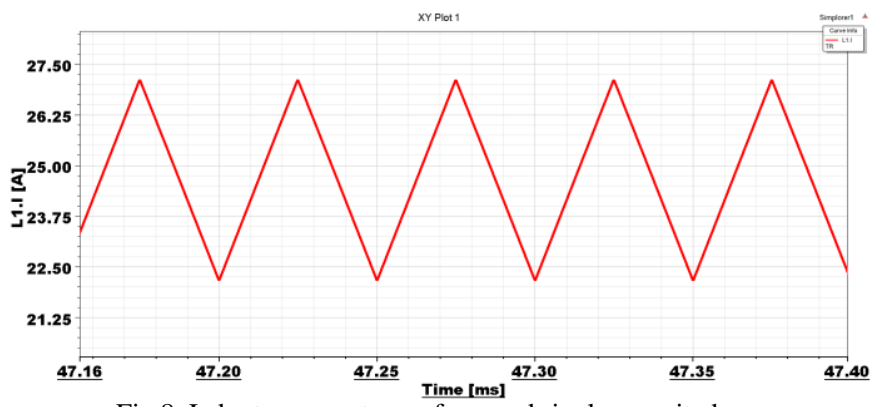

Fig.8. Inductor current waveform and ripple magnitude

The dynamic inductance graph of the modeled inductor is given in Fig. 9. Thus, approximately $60 \%$ of the roll-off of the inductor in the power electronics circuit is also confirmed with the co-simulation.

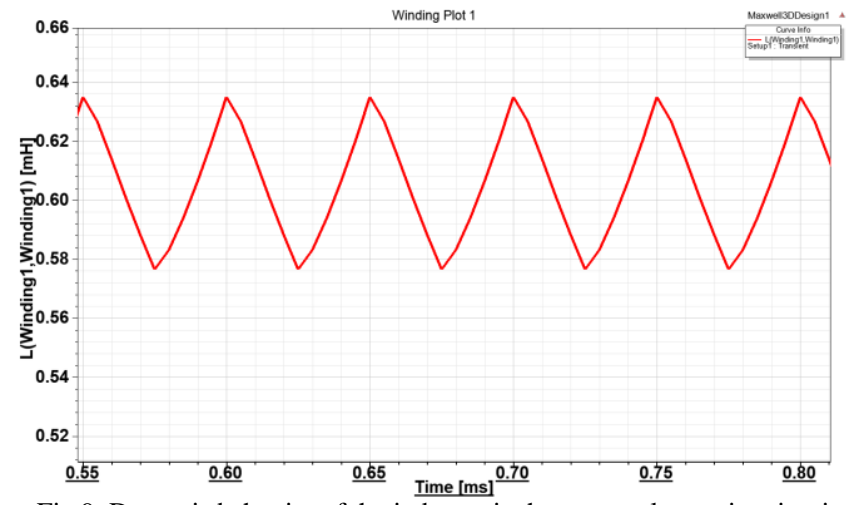

Fig.9. Dynamic behavior of the inductor in the power electronics circuit

The flux distribution in the core of the inductor designed with $3 \mathrm{~mm}$ air gap and tested for electromagnetic behavior in the power electronics circuit is given in Fig. 10. Thus, the flux value did not approach the saturation flux value and was displayed as approximately $0.2 \mathrm{~T}$ thanks to the air gaps. 


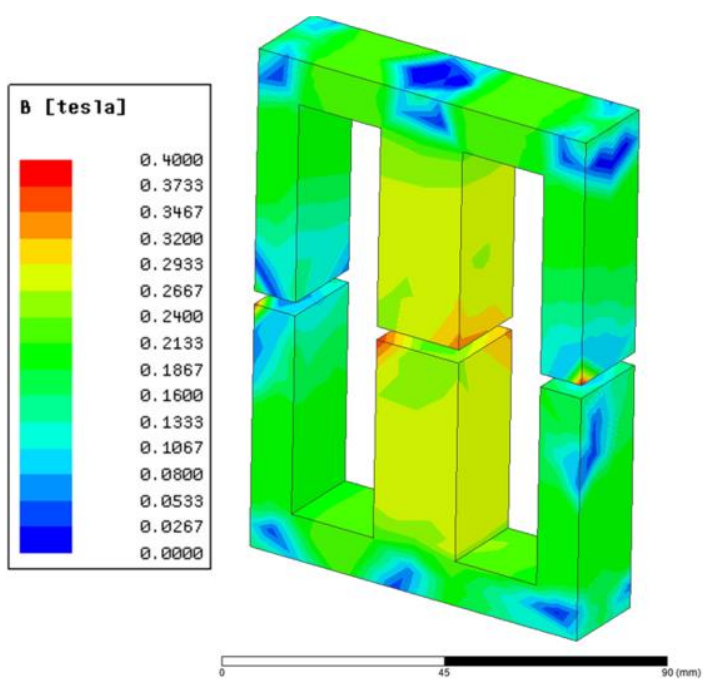

Fig.10. Flux distribution in air-gap inductor core for maximum $0.4 \mathrm{~T}$

Finally, the output voltage performance of the power electronics circuit designed as air gap inductors remains within acceptable limits in terms of the ripple value as shown in Fig. 11.

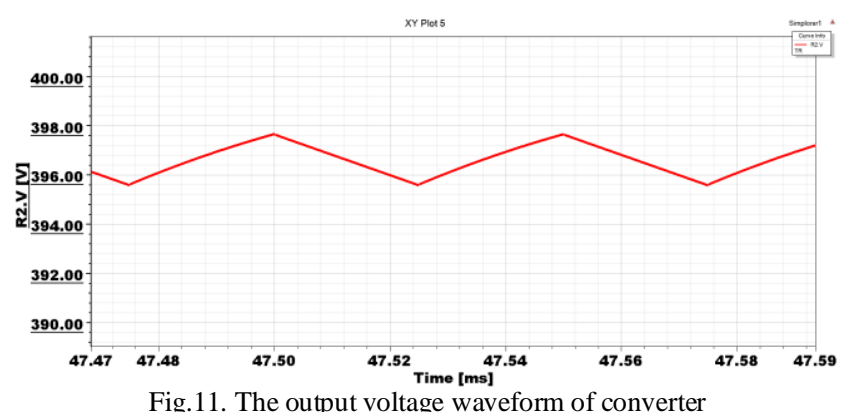

\section{CONCLUSION}

The inductors as passive circuit elements of DC-DC converter circuits are extremely important in terms of providing continuous conduction mode with the critical inductance value. In the classical design approach, the dynamic behavior of air-gapped inductors is determined according to both electrical and mechanical parameters. Also, before the prototype production, roll-off values can be seen with DC incremental tests. In this study, the parametric simulation and electromagnetic modeling of the inductors depending on number of turns, DC current and the air-gap length have been realized using FEA software. Thus, the dynamic analysis of the inductance and performance analysis in the power electronics circuit has been reported. As a result, if the inductance roll-off values are not within the acceptable limits, the most suitable value of the air-gap length can be easily determined in FEA modeling and the more realistic dynamic inductance behaviors can be seen with the cosimulations for DC-DC boost converter circuit.

The importance of this study explains the determination of air-gapped core inductor behavior before the prototype realization studies according to the theoretical information given for the inductor design and 3D electromagnetic modeling studies. As future studies, performance investigation can be done with experimental studies of an E1006028 core inductor. Also, the inductor discussed in this study is for medium frequency and high power applications. For this reason, the power electronics circuit is modeled for medium frequency $(20 \mathrm{kHz})$ and $\mathrm{kW}$ power levels.

\section{REFERENCES}

[1] M. Ashraf, N. Masoum. "High efficiency boost converter with variable output voltage using a self-reference comparator." AEU - International Journal of Electronics and Communications, vol. 68. 11, 2014, pp 1058-1064.

[2] S. Balci. "A CFD simulation of the liquid-cooled pipe conductors for the high-power and high frequency power electronic circuits." Measurement 147, 2019, doi.org/10.1016/j.measurement.2019.106885.

[3] D. IjikeOna, G. YunTian, R. Sutthaweekul, S. MohsenNaqvi. "Design and optimisation of mutual inductance based pulsed eddy current probe." Measurement, 144, 2019, pp 402-409.

[4] S. Balci. "A Comparative Simulations on the Electromagnetic and Mechanical Effects of the Various Inductor Core Forms for DC-DC Converter Circuits." Düzce University Journal of Science \& Technology, vol. 7, 2019, pp 1130-1139.

[5] M. H. Sarul, G. Yıldırmaz, R. Gülgün. "Measurement of the inductance of a coil with core at different currents by a dc chopper." Electrical Engineering, vol. 82. 5, 2000, pp 273-277.

[6] S. Dwari, S. Jayawant, T. Beechner, S. K. Miller, A. Mathew, M. Chen, J. Riehl, J. Sun. "Dynamics Characterization of Coupled-Inductor Boost DC-DC Converters." IEEE COMPEL Workshop, Rensselaer Polytechnic Institute, Troy, NY, USA, 16-19, 2006, pp 264-269.

[7] İ. Sefa, S. Balci, N. Altin. "Design of the AC Line Reactors with Finite Element Method.” Journal of Polytechnic, vol. 18. 4, 2015, pp 257-267.

[8] Z. Dang, J. A. Abu Qahouq, "Modeling and Design Guidelines of HighDensity Power Inductor for Battery Power Unit." IEEE Applied Power Electronics Conference and Exposition (APEC). Long Beach, CA, USA. 2016.

[9] Y. Du, T. Jiang, Z. Xu, "Coupled Electromagnetic and Thermal Simulation Method for a DC-DC Converter Inductor." IEEE Southeast Con 2018. St. Petersburg, FL, USA, 2018.

[10] D. Munguia, G. Healy, "Design of High Power Planar Magnetics for a 1.8KW Phase Shifted Full Bridge Converter Using Advance FEA Electromagnetics Tools.” PCIM Europe 2019, Nuremberg, Germany, 2019.

[11] B.G. You, J.S. Kim, B.K. Lee, G.B. Choi, D.W. Yoo, "Optimization of Powder Core Inductors of Buck-Boost Converters for Hybrid Electric Vehicles." Journal of Electrical Engineering \& Technology vol. 6. 4, pp 527-534, 2011.

[12] H. C. Sartori, J. E. Baggio, J. R. Pinheiro, "A Comparative Design of an Optimized Boost Inductor Taking into Account Three Magnetic Materials Technologies: Volume, Cost and Efficiency Analysis." 10th IEEE/IAS International Conference on Industry Applications. Fortaleza, Brazil, 2012.

[13] M. S. Perdigão, S. F. Ferreira, M. Martins, A. S. Mendes, J. M. Alonso, "Finite Element Analysis of a Variable Inductor for an RSCC based LED Lamp Driver.” IEEE Industry Applications Society Annual Meeting. Addison, TX, USA, 2015.

[14] Z. Dang, J. A. Abu Qahouq. "Permanent-Magnet Coupled Power Inductor for Multiphase DC-DC Power Converters." IEEE Transactions on Industrial Electronics, vol. 64. 3, 2017.

[15] Ferrit E1006028 core datasheet. http://ferroxcube.home.pl/prod/assets/e1006028.pdf.

[16] S. Balci, N. Altin, S. Özdemir, I. Sefa, "FEM Based Parametric Analysis of AC Line Reactors." IEEE (POWERENG) 4th International Conference on Power Engineering, Energy and Electrical Drives, Istanbul, 2013, pp 1328-1333.

[17] I. Sefa, S. Balci, N. Altin, S. Ozdemir, "Comprehensive analysis of inductors for an interleaved buck converter." IEEE 15th International Power Electronics and Motion Control Conference (EPE/PEMC 2012), Serbia, 2012. 
[18] A.W. Lotfi, M. A. Wilkowski. "Issues and Advances in High-Frequency Magnetics for Switching Power Supplies.” PROCEEDINGS OF THE IEEE, vol. 89. 6, 2001.

[19] V. Leonavi cius, M. Duffy, U. Boeke, S. C. Ó Mathúna. "Comparison of Realization Techniques for PFC Inductor Operating in Discontinuous Conduction Mode." IEEE Transactions on Power Electronics, vol. 19. 2, 2004.

[20] M.K. Kazimierczuk, High-frequency magnetic components, Second Edition, Wiley, Ohio, USA, 2014.

[21] M. K. Kazimierczuk, L. A. Starman. "Dynamic Performance of PWM DC-DC Boost Converter with Input Voltage Feedforward Control. IEEE Transactions on Circuits and Systems-I: Fundamental Theory and Applications." vol. 46. 12, 1999.

[22] P. Mattavelli. "Digital Control of dc-dc Boost Converters with Inductor Current Estimation." Nineteenth Annual IEEE Applied Power Electronics Conference and Exposition, APEC '04. Anaheim, CA, USA, 2004.

[23] M. Rashid, Power Electronics Devices, Circuits, And Applications Fourth Edition. NJ, USA: Pearson Education, 2014.

[24] S. Iyasu, T. Shimizu, K. Ishii, "A Novel Inductor Loss Calculation Method on Power Converters Based on Dynamic Minor Loop.” IEEE European Conference on Power Electronics and Applications. Dresden, Germany, 2005.

[25] W. K. Mo, K. M. Paasch, M. Sachmann, "Optimal inductor winding geometries for minimizing winding loss in gapped inductor designs." 19th European Conference on Power Electronics and Applications (EPE'17 ECCE Europe). Warsaw, Poland, 2017.

[26] A. Stadler, T. Stolzke, and C. Gulden, "Nonlinear Power Inductors for Large Current Crest Factors, Hindawi Publishing Corporation, Journal of Engineering", Article ID 687581, 6 pages, http://dx.doi.org/10.1155/2013/687581, 2013.

\section{BIOGRAPHIES}

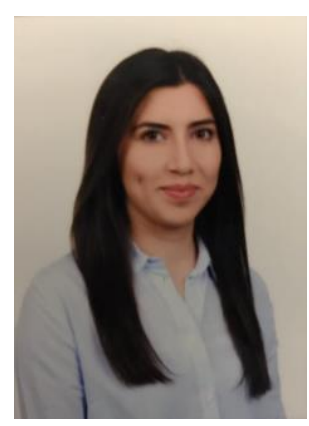

PINAR ARIKAN She received the B.S. degree in electrical and electronics engineering from Karadeniz Technical University, Trabzon, in 2017. She is currently a M.S. student in Karamanoğlu Mehmetbey Universtiy, Graduate School of Natural and Applied Sciences. Her research interests the design of coupled inductor for DC-DC converter circuits, and the electromagnetic 2D/3D modeling with FEA software.

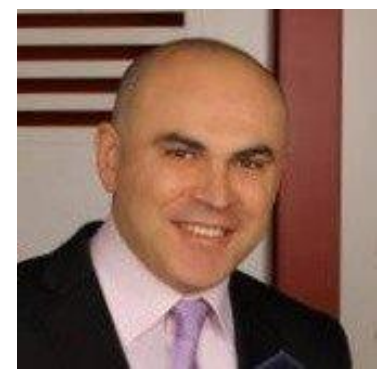

SELAMI BALCI He received the B.S., M.S. and the Ph.D. degrees in electrical education from the Gazi University, Ankara, in 1997, 2010 and 2016, respectively. Since 2018, he is currently an assistant professor at the faculty of engineering, department of electrical and electronics engineering, Karamanoğlu Mehmetbey University. His research interests include medium frequency power transformer, transformer design with the soft magnetic core material, transformer thermal analysis, inductor design, electromagnetic modeling with FEA software, and performance analysis of the power electronics circuits.

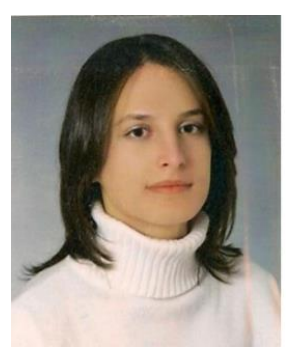

FUNDA BATTAL She received the B.S. and M.S. degrees in electrical education from the Gazi University, Ankara, in 2008 and 2011, respectively, and the Ph.D. degree in electrical and electronic engineering from Gazi University, Ankara, in 2019. Since 2011, she is a lecturer Electronics and Automation Department, Nevsehir Haci Bektas Veli University. Her research interests include transformer, core material, and transformer vibration. 